\title{
TIPO DE EMBALAGEM, UMIDADE INICIAL E PERÍODO DE ARMAZENAMENTO EM SEMENTES DE FEIJÃO
}

\section{KINDS OF PACKAGE, INITIAL MOISTURE CONTENTS AND STORAGE PERIODS OF BEAN SEEDS}

\author{
Antonio Carlos ALVES ${ }^{1}$ \\ Hiow Shong LIN²
}

\begin{abstract}
RESUMO
O presente trabalho teve por objetivo avaliar a qualidade fisiológica de sementes de feijão sob diferentes tipos de embalagens e do teor de umidade inicial das sementes armazenadas durante 21 meses em ambientes abertos nas condições climáticas do litoral do Estado de Santa Catarina. Metade de sementes de feijão, cultivar Carioca, com $15 \%$ de umidade, foram armazenadas em condições ambientais no laboratório de sementes do Departamento de Fitotecnia-CCA/UFSC, em três tipos de embalagens (saco de pano de algodão, saco de polietileno e saco de plástico grosso) e outra metade foi seca em estufa até $11 \%$ de umidade e armazenada da mesma maneira. As amostras foram coletadas trimestralmente e submetidas aos testes de umidade, germinação e vigor. Independentemente dos tipos de embalagens, as sementes encontraram seu equilíbrio higroscópico mais baixo, maior germinação e vigor quando a umidade inicial foi de $11 \%$. Independentemente da umidade inicial, as sementes encontraram seu equilíbrio higroscópico mais baixo e maior vigor na embalagem de saco de polietileno e não houve efeito da embalagem para germinação. O maior vigor foi encontrado em sementes embaladas em saco de polietileno com umidade inicial de $11 \%$. Ocorreu uma rápida redução do vigor e germinação após seis e 12 meses de armazenamento, respectivamente.
\end{abstract}

Palavras-chave: embalagem, umidade inicial, armazenamento, qualidade fisiológica da semente, Phaseolus vulgaris $\mathrm{L}$.

\begin{abstract}
The objetive of this work was to evaluate the physiological quality of bean seeds under different kinds of package, initial seed moisture contents and natural storage condition for 21 months. Bean seeds (cv. Carioca) with $11 \%$ and $15 \%$ of moisture contents were packed in three kinds of package (cloth bags of cotton, bags of polyethylene and thick plastic), then, were stored in seed laboratory of plant Science Department, Agricultural Science Center, Federal University of Santa Catarina. Seed moisture content, germination and vigor were determined in each three months until 21 months. Independently to the kinds of package and initial seed moisture contents, seeds with lower moisture contents, had higher germination and vigor. The higher seed germination and vigor were found when the initial seed moisture content was in $11 \%$. Seeds packed in polyethylene bags had higher seed vigor, however, the seed germinations were not affected by the different kinds of package. Seeds with $11 \%$ moisture contents and packed in polyethylene bag had the highest seed vigor. The seed vigor and germination decreased rapidly after six and 12 months of storage, respectively.
\end{abstract}

Key- words: package, initial seed moisture content, storage, physiological quality, Phaseolus vulgaris $L$.

\footnotetext{
${ }^{1}$ Prof. Adjunto Doutor - Departamento de Fitotecnia, CCA-UFSC. Caixa Postal 476, CEP 88040-900, Florianópolis, SC. E-mail: alves@cca.ufsc.br Autor para correspondência;

${ }^{2}$ Prof. Titular Ph.D. - Departamento de Fitotecnia, CCA-UFSC. Caixa Postal 476, CEP 88040-900, Florianópolis, SC.
} 
ALVES, A.C. e LIN, H.S. Tipo de embalagem, umidade inicial...

\section{INTRODUÇÃO}

A qualidade fisiológica de sementes aramazenadas está relacionada ao tipo de embalagem empregado. Quando as sementes são armazenadas em embalagens permeáveis, seu teor de umidade varia conforme as variações da umidade do ar. Em embalagens semi-permeáveis há alguma resistência as trocas, porém nada que impeça completamente a passagem da umidade e, em embalagens impermeáveis não há influência da umidade do ar externo sobre a semente (12). Dessa maneira, sementes de feijão acondicionadas em saco de pano e papel multifoliado, armazenadas em ambiente natural, apresentaram maiores oscilações nos níveis de umidade do que aquelas armazenadas em saco de polietileno em câmara úmida (10).

Sementes de feijão com $12 \%$ de umidade podem ser conservadas com segurança até um ano de armazenamento. Já com $10-11 \%$ de umidade, podem ser armazenadas por período maior, segundo Toledo e Marcos-Filho (13). No entanto, para armazenar sementes de feijão em embalagens impermeáveis, o máximo teor de umidade deverá ser de $9 \%$ (12). Independentemente do tipo de embalagem (sacos de pano, sacos de papel multifoliado e sacos de polietileno) e armazenamento (ambiente natural), houve redução do vigor e germinação de sementes de feijão após 17 meses de armazenamento (10). De acordo com esses autores, sementes armazenadas em câmara fria com teor de umidade inicial elevada $(14,2 \%)$, após 11 meses de armazenamento apresentaram capacidade germinativa e vigor reduzidos em relação àquelas com umidade inicial baixa $(8,5 \%)$, principalmente as acondicionadas em sacos de pano e de papel multifoliado.

A maior percentagem de germinação e vigor foi encontrada em sementes de feijão armazenadas em câmara fria por 24 e 34 meses, seguindo-se as sementes armazenadas por igual período em ambiente natural, sendo que as sementes estocadas por 48 e 58 meses estavam inviáveis (11). Esse comportamento foi atribuído às condições de armazenamento que exerceram profunda modificação no metabolismo de lipídeos e sua peroxidação durante a estocagem. Por outro lado, em silos metálicos, independentemente da germinação inicial, apenas lotes com vigor igual ou superior a $80 \%$, mantiveram a germinação dentro do padrão até o $13^{\circ}$ mês, enquanto lotes de médio a baixo vigor, apresentaram índices abaixo do padrão no $6^{\circ}$ mês de armazenamento (2). Os autores afirmaram que através do teste de vigor (envelhecimento precoce), pode-se estimar o potencial de conservação das sementes armazenadas. Barros e Lollato (3) verificaram a superioridade das embalagens herméticas, em relação ao saco comum de aninhagem, com destaque para a lata de 18 litros com tampa, no sentido de conservar a qualidade das sementes de feijão durante 10 meses em nível de propriedade.

O presente trabalho teve por objetivo avaliar o efeito de diferentes tipos de embalagens e do teor de umidade inicial das sementes, sobre a umidade, germinação e vigor de sementes de feijão, armazenadas durante 21 meses em ambiente aberto, nas condições climáticas do litoral do Estado de Santa Catarina.

\section{MATERIAL E MÉTODOS}

O experimento foi conduzido no laboratório de sementes do Centro de Ciências Agrárias da Universidade Federal de Santa Catarina. O clima do local onde o experimento foi realizado segundo Köppen é do tipo cf a, mesotérmico úmido e sem estação definida (5). A precipitação pluvial anual é de $1530 \mathrm{~mm}$, com uma evapotranspiração de $1038 \mathrm{~mm}$. A temperatura média anual é de $23,8^{\circ} \mathrm{C}$ no verão e de $16,8^{\circ} \mathrm{C}$ no inverno (5).

Metade das sementes de feijão Carioca, com grau de umidade de $15 \%$, foi retirada e embalada em saco de pano (embalagem permeável), de polietileno (embalagem semi-permeável) e de plástico grosso (embalagem impermeável) na quantidade de $3,8 \mathrm{~kg}$ por embalagem. A outra metade foi seca em estufa modelo $320 \mathrm{com}$ circulação de ar à $38^{\circ} \mathrm{C}$ até atingir umidade de $11 \%$ e embalada da mesma forma. As sementes foram armazenadas em ambiente natural dentro do laboratório, sem controle de temperatura e umidade, durante 21 meses.

O experimento foi conduzido no esquema fatorial, em delineamento de blocos ao acaso, com quatro repetições de 100 sementes para todas as variáveis estudadas. Foram utilizados os seguintes tratamentos: 1) tipos de embalagens (saco de pano de algodão, saco de polietileno $15 \mathrm{~g} \cdot \mathrm{m}^{-2}$ e saco de plástico grosso $0,015 \mathrm{~mm}$ ) e 2) umidade inicial da semente (alta $-15 \%$ e baixa $-11 \%$ ).

Procedeu-se a determinação do grau de umidade, do poder germinativo e do vigor das sementes de três em três meses, até ao 21 meses de armazenamento. O teor de umidade das sementes $(5 \mathrm{~g})$ foi determinado pelo método da estufa à $105^{\circ} \mathrm{C}$ (4), o poder germinativo de acordo com as Regras para Análise de Sementes (4), e o teste de vigor através do envelhecimento rápido. Para realização deste, foram colocadas em saco de filó quatro subamostras de 100 sementes e mantidas na câmara de envelhecimento regulada para $42^{\circ} \mathrm{C}$ com $100 \%$ de umidade relativa do ar. $O$ tempo de exposição foi de 39 horas, sendo após realizado o teste de germinação (4).

Todas as determinações descritas anteriormente foram submetidas a análise de variância. Aplicouse o F-teste com a finalidade de testar as diferenças entre os tratamentos. Para a comparação de médias adotou-se o teste de Duncan à $5 \%$ de probabilidade. 


\section{RESULTADOS E DISCUSSÃO}

A umidade das sementes armazenadas com umidade inicial de $11 \%$ mantiveram-se abaixo daquelas armazenadas com umidade inicial de 15\% (Tabela 1). No entanto, o equilíbrio higroscópico das sementes com umidade inicial de $11 \%$ ficou acima do valor original enquanto, as sementes com umidade inicial de $15 \%$ ficou abaixo desse valor (Tabelas $1 \mathrm{e}$ 2). Esse comportamento deve-se ao clima úmido do local onde foi realizado o experimento. Por outro lado, a armazenagem em saco de polietileno (semi-permeável) manteve a umidade das sementes sempre mais baixa em relação a armazenagem em saco de pano de algodão (permeável) e saco de plástico grosso (impermeável) independentemente da umidade inicial das sementes (Tabela 2 e 3). A umidade das sementes armazenadas em embalagem impermeável deveria ser inferior aos outros dois tipos de embalagens (12 e 10). Ocorre que, devido a abertura dessa embalagem para a amostragem das sementes durante o ensaio, entrava umidade e permanecia quando o mesma era fechada. Problema semelhante ocorreu com sementes de milho (7). Dessa maneira, sugere-se que a retirada de sementes para semeadura em condições de clima semelhante deve ser feita de uma só vez para embalagem impermeável.

TABELA 1 - Percentagem de umidade de sementes de feijão em função da umidade inicial e independente do tipo de embalagem, armazenadas durante 21 meses.

\begin{tabular}{cc}
\hline Umidade inicial (\%) & Umidade média $(\%)$ \\
\hline 11,0 & $13,5 \mathrm{~b}$ \\
15,0 & $14,7 \mathrm{a}$ \\
\hline
\end{tabular}

Médias seguidas pela mesma letra na coluna não diferem pelo teste de Duncan- $5 \%$.

TABELA2 - Percentagem de umidade de sementes de feijão em função do tipo de embalagem, do período de armazenamento e do teor de umidade inicial.

\begin{tabular}{|c|c|c|c|c|c|c|c|c|c|}
\hline \multirow{2}{*}{$\begin{array}{l}\text { Umidade } \\
\text { inicial } \\
(\%)\end{array}$} & \multirow{2}{*}{$\begin{array}{c}\text { Tipo de } \\
\text { embalagem }\end{array}$} & \multicolumn{8}{|c|}{ Período de armazenamento (mês) } \\
\hline & & Zero & 3 & 6 & 9 & 12 & 15 & 18 & 21 \\
\hline \multirow{3}{*}{11,0} & 1 & 11,0 & 15,0 & 15,6 & 13,2 & 15,5 & 14,2 & 14,3 & 12,9 \\
\hline & 2 & 11,0 & 11,9 & 12,2 & 12,3 & 13,7 & 12,9 & 13,2 & 14,4 \\
\hline & 3 & 11,0 & 12,9 & 12,9 & 13,0 & 14,4 & 12,3 & 12,5 & 10,7 \\
\hline \multirow{3}{*}{15,0} & 1 & 15,0 & 15,1 & 15,0 & 15,3 & 15,1 & 14,6 & 14,1 & 13,8 \\
\hline & 2 & 15,0 & 14,7 & 14,3 & 14,0 & 17,4 & 13,6 & 14,1 & 14,0 \\
\hline & 3 & 15,0 & 14,6 & 14,5 & 14,2 & 16,0 & 13,9 & 14,1 & 13,9 \\
\hline
\end{tabular}

*1 - saco de pano de algodão; 2 - saco de polietileno; 3 - saco de plástico grosso.

A germinação e o vigor das sementes foram superiores, quando armazenadas com umidade inicial de $11 \%$, em relação àquelas armazenadas com $15 \%$ de umidade inicial, independentemente do tipo de embalagem (Tabela 4). A análise de variância realizada para todo o período do ensaio mostrou que não houve diferença significativa para germinação, quando considerou-se os três tipos de embalagens, independentemente da umidade inicial das sementes (Tabela 5). No entanto, as sementes foram viáveis (germinação acima de $80 \%$ ) até aos nove meses para armazenamento em saco de pano e de polietileno e até aos seis meses para saco de plástico grosso quando armazenadas com umidade inicial de $11 \%$. A viabilidade foi apenas de seis meses com $15 \%$ de umidade inicial para os três tipos de embalagens (Tabela 6 ). A estimativa do coeficiente angular da reta (dados não apresentados), obtida através da análise de regressão, mostrou que a cada mês de armazenamento ocorreu uma perda de aproximadamente $2,4 \%$ de germinação. Dessa maneira, a partir do $12^{\circ}$ mês começou a ocorrer uma rápida redução da germinação, independentemente dos tipos de embalagens e da umidade inicial (Tabela $6)$. Esses resultados foram diferentes daqueles obtidos por Lopes et al. (11), Amaral e Baudet (1), Lin (7), Lopes et al. (9), Barros e Lollato (3), Barbosa e Borges (2) e Lopes e Capucho (10) para sementes de espécies gramíneas e leguminosas. A explicação para a discrepância desses resultados em relação ao da literatura deve-se a dois fatores. O primeiro refere-se a entrada de umidade na embalagem impermeável por ocasião da amostragem, o que modificou o comportamento da germinação das sementes, pois esperava-se melhor conservação das mesmas nesse tipo de embalagem. Outro fator importante é a composi- 
ALVES, A.C. e LIN, H.S. Tipo de embalagem, umidade inicial...

ção química diferente do feijão em relação as gramíneas $(6,9)$. Nesse aspecto, sementes de leguminosas como feijão se deterioram mais facilmen- te do que as de gramíneas. Lopes et al. (10) atribuíram esse comportamento ao metabolismo dos lipídeos e sua peroxidação durante $o$ armazenamento das sementes de feijão.

TABELA 3 - Percentagem de umidade de sementes de feijão em função do tipo de embalagem e independente da umidade inicial das sementes, armazenadas durante 21 meses.

\begin{tabular}{lc}
\hline Tipo de embalagem & Umidade média $(\%)$ \\
\hline Saco de pano de algodão & $14,3 \mathrm{a}$ \\
Saco de polietileno & $13,7 \mathrm{~b}$ \\
Saco de plástico grosso & $14,3 \mathrm{a}$ \\
\hline
\end{tabular}

Médias seguidas pela mesma letra na coluna não diferem pelo teste de Duncan- $5 \%$.

TABELA 4 - Percentagem de germinação e de vigor das sementes de feijão em função da umidade inicial e independente do tipo de embalagem, armazenadas durante 21 meses.

\begin{tabular}{lcl}
\hline \multicolumn{1}{c}{ Tipo de embalagem } & Germinação (\%) & Vigor (\%) \\
\hline Saco de pano de algodão & $69,9 \mathrm{a}$ & $40,5 \mathrm{~b}$ \\
Saco de polietileno & $73,3 \mathrm{a}$ & $50,0 \mathrm{a}$ \\
Saco de plástico grosso & $73,0 \mathrm{a}$ & $40,5 \mathrm{~b}$ \\
\hline
\end{tabular}

Médias seguidas pela mesma letra na coluna não diferem pelo teste de Duncan-5\%.

Independentemente da umidade inicial, o maior vigor das sementes foi obtido quando elas foram armazenadas em sacos de polietileno (Tabela 5). No entanto, após seis meses de armazenamento, verificou-se uma rápida redução no vigor (Tabela 7). A estimativa do coeficiente angular da reta mostrou que a cada mês de armazenamento ocorreu uma perda de $4,4 \%$ de vigor (Tabela 7 ). Para o vigor também houve interação entre umidade inicial das sementes e o tipo de embalagem. O maior vigor ocorreu quando a umidade inicial foi de $11 \%$ e a sementes estavam armazenadas em saco de polietileno (Figura 3). A perda da germinação e do vigor nessas condições foi explicada por Lin (1988b e 1990) através da absorção de água pelas sementes para atingir seu equilíbrio higroscópico, causando a deterioração da membrana plasmática das células das sementes.

TABELA 6 - Poder germinativo (\%) das sementes de feijão em função do tipo de embalagem, período de armazenamento e teores de umidade inicial.

\begin{tabular}{|c|c|c|c|c|c|c|c|c|c|}
\hline \multirow{2}{*}{$\begin{array}{c}\text { Umidade } \\
\text { inicial } \\
(\%)\end{array}$} & \multirow{2}{*}{$\begin{array}{c}\text { Tipo de } \\
\underset{*}{\text { embalagem }}\end{array}$} & \multicolumn{8}{|c|}{ Período de armazenamento (mês) } \\
\hline & & Zero & 3 & 6 & 9 & 12 & 15 & 18 & 21 \\
\hline \multirow{3}{*}{11} & 1 & 88 & 87 & 83 & 81 & 78 & 66 & 52 & 23 \\
\hline & 2 & 87 & 83 & 80 & 80 & 78 & 72 & 74 & 42 \\
\hline & 3 & 87 & 86 & 81 & 78 & 79 & 71 & 69 & 49 \\
\hline \multirow{3}{*}{15} & 1 & 90 & 82 & 81 & 77 & 79 & 54 & 57 & 25 \\
\hline & 2 & 90 & 86 & 82 & 78 & 79 & 59 & 55 & 33 \\
\hline & 3 & 90 & 84 & 82 & 79 & 72 & 57 & 65 & 25 \\
\hline
\end{tabular}

\footnotetext{
*1 - saco de pano de algodão; 2 - saco de polietileno; 3 - saco de plástico grosso.
} 
ALVES, A.C. e LIN, H.S. Tipo de embalagem, umidade inicial...

TABELA 7 - Percentagem de vigor das sementes de feijão em função do tipo de embalagem, período de armazenamento e teores de umidade inicial.

\begin{tabular}{|c|c|c|c|c|c|c|c|c|c|}
\hline \multirow{2}{*}{$\begin{array}{l}\text { Umidade } \\
\text { inicial } \\
(\%)\end{array}$} & \multirow{2}{*}{$\begin{array}{c}\text { Tipo de } \\
\text { embalagem } \\
\text { end }^{2}\end{array}$} & \multicolumn{8}{|c|}{ Período de armazenamento (mês) } \\
\hline & & Zero & 3 & 6 & 9 & 12 & 15 & 18 & 21 \\
\hline \multirow{3}{*}{11} & 1 & 84 & 79 & 72 & 51 & 27 & 14 & 5 & 0 \\
\hline & 2 & 84 & 82 & 79 & 59 & 63 & 56 & 31 & 15 \\
\hline & 3 & 84 & 82 & 78 & 61 & 64 & 67 & 25 & 19 \\
\hline \multirow{3}{*}{15} & 1 & 84 & 79 & 71 & 54 & 20 & 6 & 4 & 0 \\
\hline & 2 & 84 & 79 & 73 & 57 & 25 & 9 & 5 & 0 \\
\hline & 3 & 84 & 79 & 74 & 57 & 26 & 7 & 5 & 0 \\
\hline
\end{tabular}

*1 - saco de pano de algodão; 2 - saco de polietileno; 3 - saco de plástico grosso.

\section{CONCLUSÕES}

A partir dos resultados obtidos, podemos concluir:

- Nas condições do litoral de Santa Catarina, as sementes de feijão apresentaram viabilidade (germinação acima de $80 \%$ ) até o $9^{\circ}$ e $6^{\circ}$ mês quando a umidade inicial de armazenamento foi de $11 \%$ e $15 \%$, respectivamente, independentemente do tipo de embalagem.

- Ocorreu uma rápida redução do vigor após o $6^{\circ}$ mês de armazenamento, independentemente do tipo de embalagem e umidade inicial.

- A melhor embalagem nessas condições foi o saco de polietileno (semi-permiável).
- Os estudos indicam que com o uso de embalagens impermeáveis, as sementes devem ser utilizadas todas de uma só vez após a abertura da embalagem, o que evita o acúmulo de umidade na embalagem e a aceleração da deterioração das sementes.

\section{AGRADECIMENTOS}

Os autores agradecem a empresa Lavoura Igarashi Ltda pelo fornecimento das sementes e o ao Professor Dr. Paulo José Ogliari - Depto. de Informática e Estatística/CTC/UFSC pelo auxílio nas análises estatísticas.

\section{REFERÊNCIAS BIBLIOGRÁFICAS}

1. AMARAL, A.S., BAUDET, L.M. Efeito do teor de umidade da semente, tipo de embalagem e período de armazenamento, na qualidade da semente de soja. Revista Brasileira de Semente, Brasília, v.5, n.5, p.27-35, 1983.

2. BARBOSA, M.M.S., BORGES, J.W.M. Comportamento de sementes de feijão (Phaseolus vulgaris L.) durante o armazenamento em silos metálicos sem aeração. Informativo ABRATES, Londrina, v.1, n.4. p.23. 1991.

3. BARROS, A.S.R., LOLLATO, A.M. Conservação de sementes de feijão (Phaseolus vulgaris L.) ao nível de pequena propriedade. Informativo ABRATES, Londrina, v.1, n.4, p.23. 1991.

4. BRASIL. Ministério da Agricultura e da Reforma Agrária. Regras para análise de sementes. Brasília: SNDA/DNDV/CLAV, 1992. 365p.

5. IDE, B.Y;;ALTHOFF, D.A.;THOMÉ,V.M.R.; VIZZOTTO, V,J. Zoneamento agroclimático do Estado de Santa Catarina, 2a . Etapa. Florianópolis: EMPASC, 1980.106p.

6. LIN, S.S. Efeito de diferentes tipos de embalagens e do teor de umidade inicial sobre a qualidade fisiológica de sementes de milho (Zea mays L.), armazenadas em condições de ambiente. Agronomia Sulriograndense, PortoAlegre, v.23, n.2, p.307-317, 1988a.

7. LIN S.S. Efeito do período de armazenamento na lixiviação eletrolítica dos solutos celulares e qualidade fisiológica da semente de milho (Zea mays L.) e feijão (Phaseolus vulgaris L.). Revista Brasileira de Semente, Brasília, v.10, n.3, p.5967, 1988b.

8. LIN, S.S. Alterações na lixiviação eletrolítica, germianção e vigor da semente de feijão envelhecida sob alta umidade relativa do ar e alta temperatura. Revista Brasileira de Fisiologia Vegetal, Viçosa, v.2, n.2, p.1-6, 1990.

9. LOPES, J.C., TEIXEIRA, J.P.F., SHARIF, R.R. Efeito do armazenamento sobre a germinação, vigor, teor de lipídeos e peróxidos em sementes de Phaseolus vulgaris L. Informativo ABRATES, Londrina. v.1, n.4, p.22, 1991.

10. LOPES, J.C., CAPUCHO, M.T. Estudo sobre a conservação de sementes de feijão. Informativo ABRATES, Londrina, v.3, n.4, p.42, 1993 
ALVES, A.C. e LIN, H.S. Tipo de embalagem, umidade inicial...

11. LOPES, A.R., GIARETTA, H., SILVA, A.V., FAGUNDES, A.C. Efeito do armazenamento em câmara com umidade e temperatura controlada e em armazém sobre a qualidade de sementes de milheto (Pennisetum americanum (L.) Leeke). Agronomia Sulriograndense, Porto Alegre, v.19, n.1, p.57-69, 1983.

12. POPINIGIS, F. Fisiologia da semente. Brasília: s.n., 1985. 289p.

13. TOLEDO, F.F., MARCOS-FILHO, J. Manual das sementes: tecnologia da produção. São Paulo: Agronômica Ceres, 1977. 224p.

Recebido em 30/10/2001 Aceito em 08/12/2003 